\section{Private doubts, public support}

Washington

DAVID Kessler, commissioner of the Food and Drug Administration (FDA), is pressing ahead with reforms to the agency's drug approval process despite serious misgivings about some of them.

Documents uncovered by a panel of the US Congress that has oversight of FDA suggest that Kessler and other senior FDA officials disagree with some of the 11 changes proposed last autumn by the White House Council on Competitiveness, a body chaired by Vice President Dan Quayle. The council's job is to prevent federal regulations from imposing unnecessary burdens on industry (see Nature 354, 173; 1991).

Two of the council's recommendations involve a plan to farm out the review of new drug applications (NDAs) to outside groups and to allow local institutional review boards (IRBs), rather than the FDA, to decide when to begin human clinical trials of a new drug. Pharmaceutical companies, which have long complained about the backlog of drugs awaiting approval at FDA, welcome the reforms as a way to reduce approval times for new drugs. But Congressional critics argue that FDA is being held hostage to the political desires of an administration bent on deregulation. And consumer health group advocates fear that the changes will weaken FDA's ability to scrutinize drug applications and compromise patient safety.

Last week, Kessler told a US congressional subcommittee that any notion that he was forced to endorse these new procedures was "nonsense. These are things that I believe in, things that I believe will work", he told the House subcommittee on human resources and intergovernmental relations of the Committee on Government Operations. But preliminary investigations by the subcommittee chairman, Representative Ted Weiss (Democrat, New York), suggest that Kessler's public words are at odds with his private views.

Documents obtained under subpoena from the FDA demonstrate that Kessler was overruled by the White House after complaining about the council's recommendations to hire outside contractors to review new drug applications and to remove FDA from the direct review of some human clinical trials. An undated executive summary of the council's working group on the drug approval process noted that Kessler "strenuously objected" to a proposal that would allow companies to opt for an external review of their clinical data. And, in a letter dated 1 August 1991 to the deputy secretary of the Department of Health and Human Services (HHS), Kessler outlined similar concerns about the external review of NDAs.

"The idea may seem attractive", Kessler wrote to HHS. "But it has major problems and could well slow down reviews of new drugs, and decrease the quality and credibility of those reviews." Such an outside review would be cumbersome and inefficient, make it difficult for FDA to audit the reliability of drug application data and force FDA to rely too heavily on summaries of data, he explained. He said there are not enough qualified senior scientists to do the reviews, and that those who are available could face a conflict of interest because of their ties to drug companies.

Despite those positions, which Kessler did not repudiate at the hearing, he told the subcommittee that the FDA has begun a pilot study of the idea of contracting out clinical reviews. However, he stressed that the FDA would retain the final decision as to whether a drug is safe and effective and should be approved for marketing. Kessler said that the pilot study would compare the costs of external and in-house reviews and gauge the number of qualified and eligible reviewers. Although the Competitive Council recommended that as many as a dozen drugs receive such an external review over a period of 16 months, FDA says that it will be able to afford only two such reviews this year.

The recommendation that would allow companies to submit applications for phase 1 (initial) human clinical trials to IRBs is also controversial. If implemented, IRBs (usually at a university or hospital), not FDA, would determine whether animal data are sufficient to warrant testing an experimental drug in humans. Such a move, the Competitive Council asserts, would allow FDA to concentrate its attention and resources on drugs that survive the early stages of investigation.

Critics argue that FDA's absence could have the reverse effect and actually slow the approval process. And, while some IRBs are capable of making these judgements, most lack the necessary expertise in medicinal chemistry, pharmacology and toxicology to determine when drug testing in humans could proceed safely. Similar proposals have met with an unenthusiastic response from IRBs.

While Kessler is publicly backing the move, he expressed doubts in a letter to Louis Sullivan, secretary of HHS, dated 22 January. Anticipating that the medical community will support the idea only if IRB approval is limited to small human studies or studies for new indications of approved drugs, Kessler writes, "we [FDA] are concerned that including large studies in humans within the scope of this proposal would subject us to criticism that we are exposing patients to unreasonable risks the IRB community will not want to take responsibility for such trials".

Diane Gershon

\section{Taking Russia's pulse}

SCIENCE ministers from the more than 20 countries that belong to the Organization for Economic Cooperation and Development (OECD) have agreed to turn their considerable analytic tools upon their former enemy, the Russian Republic. Meeting earlier this month in Paris, the ministers approved a $\$ \mathbf{7 5 0 , 0 0 0}$ study of the state of science in that republic, following the model of similar studies of member countries in which the OECD examined the people, facilities, equipment and other components of the research enterprise. A US official estimated that the study would take a minimum of 18 months, and that the United States would pay its usual share of one-fourth of the total cost.

The ministers also approved a proposal from Austria to host a conference on the brain drain that threatens many of the ex-Communist countries of Eastern Europe and the former Soviet Union. The goal of both the conference and the study is to foster the exchange of scientific information and increase cooperation between the West and the new democracies in Eastern and central Europe.

J.D.M.

\section{New icebreaker}

US ANTARCTIC researchers are about to get their second major research vessel, the 308-foot Nathaniel B. Palmer, which was launched last week on its maiden voyage to the southern oceans. The new ship's first mission will be to transport US researchers to a station on a floating iceberg in the

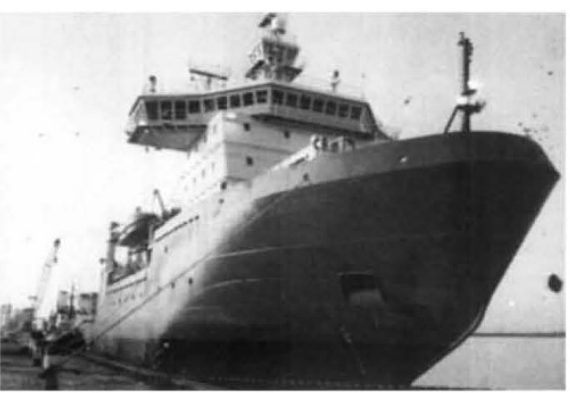

The Nathaniel B. Palmer brings NSF's Navy to full strength.

Weddell Sea, where they are studying ocean currents and the global climate. It can carry 37 researchers for up to three months (breaking three-foot-thick ice when necessary) and has more than 6,000 square feet of laboratory space, including advanced acoustical instruments and computer facilities. The US National Science Foundation operates the \$84-million vessel on a long-term lease. With the Palmer joining the veteran 218-foot Polar Duke, NSF finally has two full-time research vessels to complement its three Antarctic bases.

C.A. 